\title{
Clinical utility of folate-containing oral contraceptives
}

This article was published in the following Dove Press journal:

International Journal of Women's Health

21 April 2012

Number of times this article has been viewed

\author{
Zohra S Lassi \\ Zulfiqar A Bhutta \\ Division of Women and Child Health, \\ The Aga Khan University, Karachi, \\ Pakistan
}

Correspondence: Zulfiqar A Bhutta Division of Women and Child Health, The Aga Khan University, Karachi, Pakistan

Tel +92 2l 34864782

Fax +92 2I 34934294

Email zulfiqar.bhutta@aku.edu

\begin{abstract}
Folate is a generic term for a water-soluble B-complex vitamin which plays an important role in protein synthesis and metabolism and other processes related to cell multiplication and tissue growth. Pregnant and lactating women are at increased risk of folic acid deficiency because generally their dietary folate is insufficient to meet their physiological requirements and the metabolic demands of the growing fetus. The evidence pertaining to the reduction of the risk of neural tube defects (NTDs) due to folate is so compelling that supplementation with $400 \mu \mathrm{g}$ of folic acid to all women trying to conceive until 12 weeks of pregnancy has been recommended by every relevant authority. A recent Cochrane review has also found protective effects of folate supplementation in occurrence and reoccurrence of NTDs. Despite food fortification and targeted public health campaigns promoting folic acid supplementation, 4,300,000 new cases occur each year worldwide resulting in an estimated 41,000 deaths and 2.3 million disability-adjusted life years (DALYS). This article will review the burden and risk factors of NTDS, and the role of folate in preventing NTDs. It will also describe different modes of supplementing folate and the newer evidence of the effectiveness of adding folate in oral contraceptives for raising serum and red blood cell folate levels.
\end{abstract}

Keywords: folate, folate-containing oral contraceptives, oral contraceptives, contraceptives

\section{Burden of neural tube defects and its natural history}

Neural tube defects (NTDs), which include anencephaly, spina bifida, and encephalocele, are congenital malformations that arise during the structural development of the neural tube, a process that is completed within 28 days after conception.

Anencephaly is invariably associated with death either as stillbirth, neonatal death or occasionally postneonatal death. Encephalocele and spina bifida may be associated with neonatal death, infant death or with impairment which is frequently severe in the absence of surgery including lower limb paralysis, incontinence, convulsions and frequent central nervous system (CNS) infections. Less severe defects include spina bifida occulta which can also have long-term neurological sequelae, but rarely causes neonatal death (Table 1$){ }^{1}$

NTDs are an important cause of mortality and morbidity globally with a conservative estimated incidence of 4,300,000 new cases a year ${ }^{2}$ resulting in an estimated 41,000 deaths and 2.3 million disability-adjusted life years (DALYS). ${ }^{3}$ In addition, the lifetime direct cost associated with spina bifida is US $\$ 279,210 .{ }^{4}$ They thus comprise about one-tenth of the burden of all neonatal mortality ${ }^{5}$ and $10 \%$ of all congenital conditions and constitute the third largest congenital burden after congenital heart 
Table I Categories of neural tube defects, their causes and prognosis

\begin{tabular}{|c|c|c|c|}
\hline & Anencephaly & Encephalocele & Spina bifida \\
\hline Cause & $\begin{array}{l}\text { Failure of closure of the anterior } \\
\text { (cranial) neural arch }\end{array}$ & $\begin{array}{l}\text { Failure of closure of the anterior } \\
\text { (cranial) neural arch at a later stage } \\
\text { of embryogenesis than anencephaly }\end{array}$ & $\begin{array}{l}\text { Failure of closure of the posterior } \\
\text { (cranial) vertebral arch }\end{array}$ \\
\hline \multirow[t]{5}{*}{ Prognosis } & Stillbirth or neonatal death & Mortality from meningitis & Disability ranges from \\
\hline & & & $\begin{array}{l}\text { Neurological: sensory and motor defects, } \\
\text { learning disability and epilepsy }\end{array}$ \\
\hline & & & Orthopedics: contractures, joint \\
\hline & & & dislocations, and talipes \\
\hline & & & Functional: bladder and bowel dysfunction \\
\hline
\end{tabular}

disease and Down's syndrome. ${ }^{3}$ Over $95 \%$ of all NTDs are first occurrence; with a small proportion being repeat events in women with a previously affected pregnancy. ${ }^{6}$ Risk factors include genetic factors, environmental factors, particularly folic acid deficiency at the time of conception, diabetes and obesity and other predisposing maternal factors. ${ }^{7}$ The prevalence of NTDs varies in different racial and ethnic groups,${ }^{89}$ particularly in consanguineous marriages leading to genetic abnormalities, ${ }^{10}$ causing NTDs in current and recurrence in subsequent pregnancies. ${ }^{7,11}$ Environmental risk factors include maternal diabetes, ${ }^{12}$ use of valproic acid, ${ }^{13}$ hyperthermia,,${ }^{14,15}$ obesity, ${ }^{16-18}$ occupational exposure to agricultural ${ }^{19}$ and cleaning products. ${ }^{20,21}$ In most studies, the countries where a folate-rich diet is not available to all, NTDs are highest among the economically disadvantaged population subgroups. ${ }^{22-25}$ Even in high-income countries, lower maternal education status is associated with higher risk of NTDs. ${ }^{23,26}$ Over the past decades many countries have reported a reduction in prevalence of NTDs at birth mainly because of second-trimester screening and termination of affected pregnancies ${ }^{27}$ and partly because of folic acid supplementation. ${ }^{28}$

Certain gene polymorphisms are responsible for folate metabolism and are associated with decreased folate absorption thus increasing folate needs. One of the prominent variants are the methylene-tetrahydrofolate reductase (MTHFR) gene and Solute carrier family 19 (folate transporter), member 1 (SLC19A1) gene. ${ }^{29}$ With reduced folate intake in diet, MTHFR and SLC19A1 genetic variations are associated with increased risk of NTDs and conotruncal defects in the offspring. ${ }^{30-32}$ It was found to be associated with more than 80 genetic abnormalities (trisomy 13 and 18 and autosomal recessive syndromes, such as Meckel-Gruber). On the other hand, environmental factors, including nutrition, are thought to contribute to about $5 \%$ to $10 \%$ of total birth defects. ${ }^{33}$

These conditions can be diagnosed antenatally. Elevated concentration of alpha-feto-protein in maternal serum can raise the suspicion of NTD; the diagnosis can further be established by ultrasound examination during the second trimester of pregnancy. Unfortunately, these tests are not routinely done in most developing countries as yet. ${ }^{34-36}$ However, the combinations of maternal serum screening programs and sonographic findings have enabled the prenatal diagnosis of spina bifida in more than $90 \%$ of cases..$^{37}$ Although the prenatal diagnosis of spina bifida maximizes the reproductive options for women, it is yet unclear which fetuses would benefit from prenatal therapy, because the natural history and the sonographic signs of progressive neurologic damage have not been well characterized.

\section{Role of folic acid in prevention of neural tube defects}

Folate is a generic term for a water soluble B-complex vitamin, and it serves as co-factor in transfer of single carbon during the methylation cycle responsible for the synthesis of DNA, neurotransmitters, and gene expression. ${ }^{38,39}$ Folate also plays an important role in protein synthesis and metabolism and other processes related to cell multiplication and tissue growth. ${ }^{40}$ The main consequence of folate deficiency in adults is megaloblastic anemia, characterized by abnormally large red cell precursors in the bone marrow and larger than normal red cells in the peripheral blood. The methylation of homocysteine to produce methionine (both essential amino acids) uses 5-Methylene-tetrahydrofolate (5-MTHF) (folate and folic acid are metabolized to 5-MTHF during its passage across the intestinal mucosa) as the methyl donor in the reaction. In folate deficiency, homocysteine accumulates in the serum and is found to be associated with an increased risk in cardiovascular disease, ${ }^{41}$ late pregnancy complications such as pre-eclampsia, ${ }^{42-44}$ and NTDs around the time of conception. ${ }^{40}$

Pregnant and lactating women are at increased risk of folic acid deficiency because generally their dietary folate is insufficient to meet the physiological requirements and 
the metabolic demands of the mother and the growing fetus. ${ }^{45,46}$

In 1991, a multicenter, multinational randomized prevention trial by the British Medical Research Council (MRC) Vitamin Study Group, presented the first beneficial impacts of folic acid supplementation. ${ }^{46}$ The study was initiated in 1983 and was halted in 1991, when it was felt that the results warranted the prescription of folic acid supplementation to all study participants. The study enrolled 1817 women who had a previous pregnancy with an infant or fetus with a neural tube abnormality and were planning another pregnancy. In this study, one group was given $4000 \mu \mathrm{g}$ of folic acid, the second group a multivitamin with $4000 \mu \mathrm{g}$ of folic acid, the third group was given no supplementation, while the final group received a multivitamin without folic acid. The analysis of the trial results showed that folic acid supplementation was associated with a $71 \%$ reduction in NTDs. The study also demonstrated that such results were achieved only when supplementation began before conception and continued through the first three months of the pregnancy.

In a span of a year, another major trial from Hungary presented their results of folic acid supplementation on women without a previous history of NTD pregnancy. The results from this trial indicated that a multiple micronutrient supplement containing $800 \mu \mathrm{g}$ of folic acid prevented the occurrence of NTDs. ${ }^{47}$

While maternal intake of folate and folic acid is specifically associated with a decreased risk for NTDs, the results from those trials showed that it also provides protection for other selected birth defects. Approximately half of the birth defects are limited to a single organ and the other half frequently present additional birth defects. ${ }^{48}$ Affected infants also face difficulty with feeding and later with speech development, hearing and tooth formation. Malnutrition and infection can further lead to severe illness and, in some cases, death. ${ }^{48}$

A recent Cochrane review of five trials involving 6105 women (1949 with a history of a pregnancy affected by an NTD and 4156 with no history of NTDs), shows a protective effect of daily folic acid supplementation in doses ranging from $360 \mu \mathrm{g}$ to $4000 \mu \mathrm{g}$ a day, with and without other vitamins and minerals, before conception and up to 12 weeks of pregnancy, for preventing the occurrence of NTDs by $72 \%$ (relative risk [RR] 0.28; 95\% confidence intervals [CI]: 0.15-0.52) and reoccurrence by $68 \%$ (RR 0.32; 95\% CI: $0.17-0.60) .{ }^{49}$

Another review published in International Journal of Epidemiology in 2010 presented the meta-analysis of eight, population based observational studies examining the impact of folic acid fortified food and reported reduced NTDs incidence (RR 0.54; 95\% CI: 0.46-0.63)..$^{50}$

\section{Sources of folic acid and rationale for the fortification of oral contraceptives}

Folate is naturally present in legumes, lentils, kidney beans, green peas, corn, beets, leafy green vegetables (such as spinach, broccoli, iceberg lettuce, asparagus, and turnip greens) and some citrus fruits and juices (such as oranges, strawberries, and tomato). Folic acid is the synthetic and most stable form of folate and is often used in supplements and fortified foods. The bioavailability of folic acid is approximately $70 \%$ higher in fortified foods than that of folate naturally contained in foods, although there are wide variations depending on the methodology used in the measurement. ${ }^{51}$

In 1992, after the emergence of evidence of reduced occurrence of NTDs with folic acid supplementation, the World Health Organization (WHO) recommended $400 \mu \mathrm{g}$ of folic acid to all women trying to conceive until 12 weeks of pregnancy. ${ }^{52}$ Since then daily supplementation with folic acid, in addition to iron, is routinely recommended for all pregnant women to prevent anemia. ${ }^{53}$ Women are usually supplemented with folic acid tablets, however, in many countries governments have also introduced the concept of folate-fortified food programs, in which folic acid is added to flour, maize, or cereals to increase serum folate levels in the population.

While fortification is felt to be the best way to ensure that women of child-bearing age receive supplementation in the months preceding pregnancy and in the critical window when a woman might not know that she is pregnant, folic acid supplementation does not ensure this. Women not on folate supplementation who unintentionally become pregnant may be late in starting folate supplementation, and thus fail to reach the required levels to reduce the risk of NTDs, even if they initiate oral supplementation the moment their pregnancy is established.

As most women of reproductive age do not get adequate amounts of folate in their diets and do not seek preconceptional care, it is obvious that newer approaches are needed to reach women at risk for pregnancy. Hence recently, fortifying oral contraceptive with folate was tested and recommended by the United Nations and the US Food and Drug Administration (FDA) with the reason that women may become pregnant during use or shortly after discontinuation, possibly before seeking preconception counseling from their healthcare provider. It is particularly important for women 
who want to use an oral contraceptive, to offer them daily folate supplementation. The oral contraceptive as a vehicle to supply folate is important because its users are sexually active and it is the most popular method of birth control, especially among young women, who are the age group with the greatest number of pregnancies both intended and unintended. It not only raises plasma and red blood cells (RBC) folate levels but also provides required folate levels until women adopt another effective contraceptive method or become pregnant and initiate folic acid supplementation.

\section{Safety, tolerability and efficacy studies on folate containing oral contraceptives}

In 2010, the FDA approved Beyaz ${ }^{\circledR}$ and $\mathrm{Safyral}^{\circledR}$ (Bayer Health Care Pharmaceuticals Inc, Wayne, NJ) oral contraceptives, which have both estrogen (20 $\mu$ g ethinyl estradiol) and progestin ( $3000 \mu \mathrm{g}$ of drospirenone) and also contain a folate (451 $\mu \mathrm{g}$ levomefolate calcium - also known as 5-MTHF and L-methylfolate). Two clinical trials have examined the effects of these folate-containing oral contraceptives on $\mathrm{RBC}$ folate levels which became the basis of this drug aproval..$^{54-57}$

The US Benefit study compared an oral contraceptive containing drospirenone and ethinyl estradiol plus folate with the nonfolate-fortified version of the oral contraceptive in a multicenter, double-blind, randomized activecontrolled trial on 379 healthy women aged 18-40 years who had been exposed to folate-fortified food..$^{57,58}$ Folate levels were assessed in the plasma and RBC every 2 weeks for the 24-week study period. The women using the folatefortified oral contraceptives demonstrated significant increase $(15.8 \mathrm{nmol} / \mathrm{L})$ in serum folate levels. These levels were consistently maintained throughout the study period. In the nonfolate-fortified arm, plasma folate levels decreased by $2.2 \pm 14.6 \mathrm{nmol} / \mathrm{L}$. Significant differences were also seen in the mean RBC folate levels. In the control group, RBC folate levels increased by $34.3 \mathrm{nmol} / \mathrm{L}$, while in the folate-fortified oral contraceptive users, a mean increase from baseline of $419.9 \pm 347 \mathrm{nmol} / \mathrm{L}(P<0.001)$ was observed.

The European Long-term Folate Study, on the other hand, compared the combination of folate in an oral contraceptive given orally in a cyclic regimen for 24 weeks ( 6 cycles), with the same oral contraceptive administered separately with folic acid tablets in German women who had no exposure to folate-fortified food. ${ }^{54,55}$ It was a double-blind, 24-week trial followed by an open-label 20 -week follow-up with a nonfortified oral contraceptive to evaluate the elimination of folate from the body over time. At each point in time, the folate-fortified oral contraceptive women had higher levels of folate in both serum and RBC than women who took the folic acid supplements in addition to oral contraceptives. During the second phase of follow up, folate levels were found to be diminished but remained over the baseline levels.

While the importance of folate-fortifying oral contraceptives was established by these two trials and the persistence of the elevation in folate levels was quantified, for some clinicians, supplementing oral contraceptives with folate seems counterintuitive. Notwithstanding, birth control pills represent the most popular contraceptive choice, although they have a relatively high failure rate. Thus, an oral contraceptive that contains folate has appeal and full potential to supplement women with folate at the time of conception.

Given the potential individual and public health benefits, folate-containing oral contraceptives have some overlapping adverse reactions across three indications: contraception, acne, and folate supplementation. The most common treatmentemergent adverse reactions are headache/migraine, menstrual irregularities (spotting, metrorrhagia, and menorrhagia), nausea/ vomiting, and breast pain/tenderness. ${ }^{59}$ At the same time, oral contraceptives are contraindicated in women with a high risk of arterial or venous thrombotic diseases, undiagnosed abnormal uterine bleeding, breast cancer or other hormone-sensitive cancer, liver tumors (benign or malignant) or liver disease, conditions that predispose to hyperkalemia (ie, renal impairment, hepatic dysfunction, and adrenal insufficiency), or who are pregnant. ${ }^{59}$

\section{Conclusions and future directions}

Neural tube closure occurs during the first month after conception, often before a woman is aware of her pregnancy status. The potential to reduce the incidence of NTDs with folate supplementation is well established based on a body of evidence derived from randomized, controlled trials. Every relevant authority recommends that all women of childbearing potential consume at least $400 \mu \mathrm{g}$ of folic acid daily. There are many ways to obtain supplemental folic acid. The folate-containing oral contraceptive is a novel way to increase folic acid levels in women of childbearing age who choose birth control pills for contraception. While the FDA has approved this drug based on two clinical trials from developed countries, the drug still requires assessment in terms of its efficacy and effectiveness in different age groups and in regions with low contraceptive prevalence rates. This might not be effective in the context of the developing world as contraceptive usage rates are not comparable to the developed 
world. Coverage rates need to be improved for contraceptives in these regions; also efforts need to be made to strategize effective means of folic acid delivery in these regions.

\section{Disclosure}

The authors report no conflicts of interest in this work.

\section{References}

1. Kulkarni A, Ehrenkranz RA, Bhandari V. Effect of introduction of synchronized nasal intermittent positive-pressure ventilation in a neonatal intensive care unit on bronchopulmonary dysplasia and growth in preterm infants. Am J Perinatol. 2006;23(4):233-240.

2. Jegatheesan P, Keller RL, Hawgood S. Early variable-flow nasal continuous positive airway pressure in infants $\leq 1000$ grams at birth. J Perinatol. 2006;26(3):189-196.

3. World Health Organisation. The global burden of disease: 2004 update. 2008. Available from: http://www.who.int/healthinfo/global_burden_ disease/GBD_report_2004update_full.pdf. Accessed on December 15, 2011.

4. Ouyang L, Grosse SD, Armour BS, Waitzman NJ. Health care expenditures of children and adults with spina bifida in a privately insured US population. Birth Defects Res A Clin Mol Teratol. 2007;79(7): 552-558.

5. Finan A, Clarke TA, Matthews TG, et al. Strategies for reduction of neonatal mortality. Ir J Med Sci. 1999;168(4):265-267.

6. Wald NJ. Folic acid and the prevention of neural-tube defects. $N$ Engl J Med. 2004;350(2):101-103.

7. van der Linden IJM, Afman LA, Heil SG, Blom HJ. Genetic variation in genes of folate metabolism and neural-tube defect risk. Proc Nutri Soc. 2006;65(02):204-215.

8. Buccimazza SS, Molteno CD, Dunne TT, Viljoen DL. Prevalence of neural tube defects in Cape Town, South Africa. Teratology. 1994; 50(3):194-199.

9. Chatkupt S, Skurnick JH, Jaggi M, Mitruka K, Koenigsberger MR, Johnson WG. Study of genetics, epidemiology, and vitamin usage in familial spina bifida in the United States in the 1990s. Neurology. 1994;44(1):65-65.

10. Milunsky A, Alpert E, Neff RK, Frigoletto FD Jr. Prenatal diagnosis of neural tube defects: IV. Maternal serum alpha-fetoprotein screening. Obstet Gynecol. 1980;55(1):60-66.

11. Hall J, Solehdin F. Folic acid for the prevention of congenital anomalies. Eur J Pediatr. 1998;157(6):445-450.

12. Becerra JE, Khoury MJ, Cordero JF, Erickson JD. Diabetes mellitus during pregnancy and the risks for specific birth defects: a populationbased case-control study. Pediatrics. 1990;85(1):1-9.

13. Lammer EJ, Sever LE, Oakley GP Jr. Valproic acid. Teratology. 1987;35(3):465-473.

14. Edwards MJ, Shiota K, Smith MSR, Walsh DA. Hyperthermia and birth defects. Reprod Toxicol. 1995;9(5):411-425.

15. Graham JM Jr, Edwards MJ. Teratogen update: gestational effects of maternal hyperthermia due to febrile illnesses and resultant patterns of defects in humans. Teratology. 1998;58(5):209-221.

16. Shaw GM, Velie EM, Schaffer D. Risk of neural tube defectaffected pregnancies among obese women. JAMA. 1996;275(14): 1093-1096.

17. Watkins ML, Scanlon KS, Mulinare J, Khoury MJ. Is maternal obesity a risk factor for anencephaly and spina bifida? Epidemiology. 1996;7(5): $507-512$.

18. Werler MM, Louik C, Shapiro S, Mitchell AA. Prepregnant weight in relation to risk of neural tube defects. JAMA. 1996;275(14):1089-1092.

19. Brender JD, Felkner M, Suarez L, Canfield MA, Henry JP. Maternal pesticide exposure and neural tube defects in Mexican Americans. Ann Epidemiol. 2010;20(1):16-22.
20. Blatter BM, Roeleveld N, Zielhuis GA, Mullaart RA, Gabreëls FJM. Spina bifida and parental occupation. Epidemiology. 1996;7(2): 188-193.

21. Shaw GM, Nelson V, Olshan AF. Paternal occupational group and risk of offspring with neural tube defects. Paediatr Perinat Epidemiol. 2002;16(4):328-333.

22. Laurence KM, Carter CO, David PA. Major central nervous system malformations in South Wales. II. Pregnancy factors, seasonal variation, and social class effects. Br J Prev Soc Med. 1968;22(4):212-222.

23. Wasserman CR, Shaw GM, Selvin S, Gould JB, Syme SL. Socioeconomic status, neighborhood social conditions, and neural tube defects. Am J Public Health. 1998;88(11):1674-1680.

24. Vrijheid M, Dolk H, Stone D, Abramsky L, Alberman E, Scott JES. Socioeconomic inequalities in risk of congenital anomaly. Arch Dis Child. 2000;82(5):349-352.

25. Elwood JM, Little J, Elwood JH. Epidemiology and Control of Neural Tube Defects. New York, NY: Oxford University Press; 1992.

26. Grewal J, Carmichael SL, Song J, Shaw GM. Neural tube defects: an analysis of neighbourhood- and individual- level socio-economic characteristics. Paediatr Perinatal Epidemiol. 2009;23(2):116-124.

27. ChanA, Robertson EF, HaanEA, Keane RJ, RanieriE, CarneyA. Prevalence of neural tube defects in South Australia, 1966-1991: effectiveness and impact of prenatal diagnosis. Br Med J. 1993;307(6906):703-706.

28. Morris JK, Wald NJ. Prevalence of neural tube defect pregnancies in England and Wales from 1964 to 2004. J Med Screen. 2007;14(2): 55-59.

29. Chango A, Emery-Fillon N, de Courcy GP, et al. A polymorphism $(80 \mathrm{G}->\mathrm{A})$ in the reduced folate carrier gene and its associations with folate status and homocysteinemia. Mol Genet Metab. 2000;70(4): $310-315$.

30. van der Put NMJ, Gabreëls F, Stevens E, et al. A second common mutation in the methylenetetrahydrofolate reductase gene: an additional risk factor for neural-tube defects? Am J Human Genetics. 1998;62(5):1044-1051.

31. Van Beynum IM, Kapusta L, Den Heijer M, et al. Maternal MTHFR $677 \mathrm{C}>\mathrm{T}$ is a risk factor for congenital heart defects: effect modification by periconceptional folate supplementation. Eur Heart J. 2006;27(8):981-987.

32. Botto LD, Olney RS, Erickson JD. Vitamin supplements and the risk for congenital anomalies other than neural tube defects. Am JMed Genet $C$ (Semin Med Genet). 2004;125:12-21.

33. Bale J, Stoll B, Lucas A, editors. Reducing Birth Defects: Meeting the Challenge in the Developing World. Washington, DC: The National Academies Press; 2003.

34. Modell B, Kuliev AM. Impact of public health on human genetics. Clin Genet. 1989;36(5):286-298.

35. Alwan A, Modell B. Community Control of Genetic and Congenital Disorders. Alexandria, Egypt: WHO Regional Office for the Eastern Mediterranean; 1997.

36. Ahman E, Zupan J. Neonatal and Perinatal Mortality. Geneva, Switzerland: World Health Organization; 2006.

37. Milunsky A, Canick JA. Maternal serum screening for neural tube and other defects and fetal chromosome abnormalities. West $J$ Med. 1993;159(3):312-317.

38. Duthie SJ. Folic acid deficiency and cancer: mechanisms of DNA instability. Br Med Bull. 1999;55(3):578-592.

39. Pitkin RM. Folate and neural tube defects. Am J Clin Nutr. 2007; 85(1):285S-288S.

40. De Benoist B. Conclusions of a WHO Technical Consultation on folate and vitamin B12 deficiencies. Food Nutr Bull. 2008;29(Suppl 2): S238-S244.

41. Refsum H, Smith AD. Are we ready for mandatory fortification with vitamin B-12? Am J Clin Nutr. 2008;88(2):253-254.

42. Makedos G, Papanicolaou A, Hitoglou A, et al. Homocysteine, folic acid and B12 serum levels in pregnancy complicated with preeclampsia. Arch Gynecol Obstet. 2007;275(2):121-124. 
43. Patrick TE, Powers RW, Daftary AR, Ness RB, Roberts JM. Homocysteine and folic acid are inversely related in black women with preeclampsia. Hypertension. 2004;43(6):1279-1282.

44. Tamura T, Picciano MF. Folate and human reproduction. Am J Clin Nutr. 2006;83(5):993-1016.

45. Calonge N, Petitti DB, DeWitt TG, et al. Folic acid for the prevention of neural tube defects: US Preventive Services Task Force recommendation statement. Ann Intern Med. 2009;150(9):626-631.

46. Wald N, Sneddon J, Densem J, Frost C, Stone R. Prevention of neural tube defects: results of the Medical Research Council Vitamin Study. Lancet. 1991;338(8760):131-137.

47. Czeizel AE, Dudas I. Prevention of the first occurrence of neural-tube defects by periconceptional vitamin supplementation. $N$ Engl J Med. 1992;327(26):1832-1835.

48. Shibuya K, Murray CJL. Low birth weight. In: Murray CJL, Lopez AD, editors. Health Dimensions of Sex and Reproduction. Global Burden of Disease and Injury Series. Cambridge: MA, Harvard University Press; 1998.

49. De-Regil LM, Fernandez-Gaxiola AC, Dowswell T, Pena-Rosas JP. Effects and safety of periconceptional folate supplementation for preventing birth defects. Cochrane Database Sys Reviews. 2010; 10:CD007950.

50. Blencowe H, Cousens S, Modell B, Lawn J. Folic acid to reduce neonatal mortality from neural tube disorders. Int J Epidemiol. 2010; 39(Suppl 1):i110-i120.

51. McNulty H, Pentieva K. Folate bioavailability. Proc Nutr Soc. 2004; 63(4):529-536.

52. World Health Organization. Prevention of Neural Tube Defects. Standards for Maternal and Neonatal Care. Geneva, Switzerland: World Health Organization; 2009.
53. Unicef, United Nations, World Health Organization. Iron Deficiency Anaemia: Assessment, Prevention, and Control: A Guide for Programme Managers. Geneva, Switzerland: World Health Organization; 2001

54. Taylor TN, Farkouh RA, Graham JB, Colligs A, Lindemann M, Lynen R, Candrilli SD. Potential reduction in neural tube defects associated with use of Metafolin-fortified oral contraceptives in the United States. Am J Obstet Gynecol. 2011; 205(5):460.e1-8.

55. Diefenback K, Trummer D, Ebert F, Lissy M, Rohde B, Blode H. Changes in folate levels following cessation of Yasmin and levomefolate calcium $0.451 \mathrm{mg}$ or folic acid $400 \mathrm{mcg}$ coadministration. Eur J Contracept Reprod Health Care. 2010;15(Suppl 1):157-158.

56. FAD Beyaz Highlights of Prescribing Information; 2010. http://www. accessdata.fda.gov/drugsatfda_docs/label/2010/022532s0001bl.pdf. [Accessed on March 22, 2012].

57. Marr J, Sampson-Landers C, Diefenbach K, Trummer D, Bart S, Blode H. Folate and homocysteine levels after 24 weeks administration of YAZ levomefolate calcium $0.451 \mathrm{mg}$. Eur J Contracept Reprod Health Care. 2010;15(Suppl 1):159.

58. Bart S Sr, Marr J, Diefenbach K, Trummer D, Sampson-Landers C. Folate status and homocysteine levels during a 24-week oral administration of a folate-containing oral contraceptive: a randomized, doubleblind, active-controlled, parallel-group, US-based multicenter study. Contraception. 2010;85(1):42-50.

59. Bayer HealthCare Pharmaceuticals. Beyaz prescribing information. 2010. Available from: http://berlex.bayerhealthcare.com/html/products/ pi/fhc/Beyaz_PI.pdf. Accessed February 10, 2012.
International Journal of Women's Health

\section{Publish your work in this journal}

The International Journal of Women's Health is an international, peerreviewed open-access journal publishing original research, reports, reviews and commentaries on all aspects of women's healthcare including gynecology, obstetrics, and breast cancer. Subject areas include: Chronic conditions (migraine headaches, arthritis, osteoporosis);

\section{Dovepress}

Endocrine and autoimmune syndromes; Sexual and reproductive health; Psychological and psychosocial conditions. The manuscript management system is completely online and includes a very quick and fair peer-review system. Visit http://www.dovepress.com/ testimonials.php to read real quotes from published authors. 